\title{
Long-Term Follow-Up of Patients with a History of Near Fatal Episodes; Can Inhaled Corticosteroids Reduce the Risk of Death from Asthma?
}

\author{
Kyosuke Ishihara, Tsuyoshi Hasegawa, Miki OKazaki, Nobuyuki KataKami, \\ Hiroko SAKAMOTO, Bun-ichi UmEDA and Hitoshi NaKaI
}

\begin{abstract}
We retrospectively studied the use of inhaled corticosteroids in patients who experienced near fatal episodes (NFE) to determine whether such therapy reduces the risk of death. Forty-eight patients who had near fatal episodes of asthma between January 1981 and December 1989 were divided into two groups. Group A comprised 19 patients who received beclomethasone dipropionate (BDP) daily (mean dose of BDP: $687 \mu \mathrm{g} /$ day: 200-2,000) following NFE, and Group B, 28 patients who did not take BDP or who took less than $6 \mathrm{mg} \mathrm{BDP/month.} \mathrm{During} \mathrm{the} \mathrm{follow-up} \mathrm{period} \mathrm{(Group}$ A: 82.9 months, Group B: 66.2 months), no patients in Group A died, but eight deaths occurred in Group B (mean period between near fatal episode and death was 31.5 months: 12-66). These results suggest that the regular use of inhaled corticosteroids, even at low doses, may reduce the risk of death in patients who experience NFE.
\end{abstract}

(Internal Medicine 34: 77-80, 1995)

Key words: low dose, beclomethasone dipropionate, rapid progression

\section{Introduction}

Asthma patients who are not well controlled suffer poor quality of life and a severe attack may result in death. Death from asthma has been receiving increased attention since the 1960 's. Despite increasing rates of death, the actual cause of death is still unknown. However, it has been estimated that nearly $80 \%$ of deaths from asthma could be prevented $(1,2)$. Medical practitioners must recognize the risk factors and manage their patient well, minimizing the risk of death from asthma. The focus remains on prevention (3).

Chronic inflammation of the airway plays an important role in the pathogenesis of asthma, and inhaled corticosteroids, which are used topically with fewer systemic side effects, should be regarded as the drug of first choice (4). Long-term use of inhaled corticosteroids results in a significant improvement in asthmatic conditions $(5,6)$. A recent Canadian study suggested that inhaled corticosteroid use is effective in preventing death and near fatal asthma (7).

Earlier studies on death from asthma have shown increased mortality among patients who had previously experienced near fatal episodes $(1,2,8-10)$. We studied the use of inhaled corticosteroids retrospectively in patients following near fatal episodes to determine whether such therapy reduces the risk of death from asthma.

\section{Patients and Methods}

Fifty-eight patients were admitted to our ICU for near fatal asthma attack between January 1981 and December 1989. Some patients experienced more than one attack; in total we treated 78 attacks during this period. Near fatal attack was defined as patients who were unconscious or requiring intubation on arrival. A longitudinal survey of 47 out of 58 patients who have been followed up regularly at Kobe City General Hospital was performed. The remaining 11 out of the 58 either died or were not followed up at Kobe City General Hospital.

We examined the patient records for details of their prescriptions and retrospectively divided the patients into two groups. In Group A all patients took various doses of beclomethasone dipropionate (BDP) daily. Group B consisted of patients who were either not given BDP or who inhaled BDP infrequently, and who received less than one 120-dose meter dose inhaler containing $6 \mathrm{mg}$ of BDP per month.

From the Department of Respiratory Diseases, Kobe City General Hospital, Kobe Received for publication July 20, 1994; Accepted for publication October 7, 1994

Reprint requests should be addressed to Dr. Kyosuke Ishihara, the Department of Respiratory Diseases, Kobe City General Hospital, Minatojimanakamachi 4-6, Chuo-ku, Kobe 650 
For the patients who suffered a near fatal episode on more than one occasion, the first episode was considered the outcome event.

\section{Results}

In Group A, ten patients were male and nine were female; the mean age was 48.4 years and the mean asthma history was 13.1 years. In Group B, eighteen patients were male and ten were female; the mean age was 49.2 years and the mean asthma history was 15.8 years. Two male patients in each group were current smokers. Seven of 19 patients in Group A and seven out of 28 patients in Group B had taken oral steroids every day (prednisolone, less than $10 \mathrm{mg} /$ day). Two patients in Group A (10.5\%) and four in Group B (14.3\%) had a history of near fatal episodes prior to this study. Mean frequency of admission during the year prior to the near fatal episodes was 0.84 times/ year in Group A and 0.62 times/year in Group B.

Most patients in both groups took some form of therapy regularly or as required, including inhaled beta-agonist, oral beta-agonist, theophyllin and anti-allergic agents. There were no significant differences in prescriptions of oral antiasthmatics between Group A and Group B. The frequency of on demand beta-agonist inhaler use was varied in both groups. During follow-up periods, oral steroids were withdrawn in two patients in Group A and one in Group B who had taken them regularly (Table 1).

The mean dose of BDP in Group A was $687 \pm 451 \mu \mathrm{g} / \mathrm{day}$ (200-2,000). Mean observation periods were 82.9 months in Group A and 66.2 months in Group B. Mean admission times

Table 1. Clinical Characteristics of Patients who Have Experienced Near Fatal Episodes between Jan. 1981 and Dec. 1989 at Kobe City General Hospital

\begin{tabular}{|c|c|c|c|}
\hline & & Group A & Group B \\
\hline \multirow{2}{*}{\multicolumn{2}{|c|}{$\begin{array}{l}\text { Sex: male } \\
\text { female }\end{array}$}} & 10 & 18 \\
\hline & & 9 & 10 \\
\hline \multicolumn{2}{|l|}{ Age: } & $48.4(15.8)$ & $49.2(6.5)$ \\
\hline \multicolumn{2}{|l|}{ Current smoker } & 2 & 2 \\
\hline \multicolumn{2}{|c|}{ Duration of disease (years) } & $13.1(9.2)$ & $15.8(10.7)$ \\
\hline \multicolumn{2}{|l|}{ History of NFE (\%) } & $2(10.5)$ & $4(14.3)$ \\
\hline \multicolumn{4}{|c|}{ Frequency of admissions } \\
\hline $\begin{array}{l}\text { Oral steroid } \\
\text { before/after NFE } \\
\text { (deaths) }\end{array}$ & $\begin{array}{l}\text { None } \\
\text { on attack } \\
\text { Continuous }\end{array}$ & $\begin{array}{l}3(0) / 7(0) \\
9(0) / 7(0) \\
7(0) / 5(0)\end{array}$ & $\begin{array}{r}10(3) / 9(2) \\
11(2) / 13(3) \\
7(3) / 6(3)\end{array}$ \\
\hline $\begin{array}{l}\text { Other anti-asthmati } \\
\text { Theophyllin/beta- }\end{array}$ & s (per oral) & & \\
\hline /anti- & & 11 & 15 \\
\hline Theophyllin/beta- & & 8 & 13 \\
\hline
\end{tabular}

( ): SD.

Group A was defined as patients who took various doses of BDP daily. Group B was defined as patients who were either not given BDP or who inhaled BDP infrequently, and patients who received less than one 120dose meter dose inhaler containing $6 \mathrm{mg}$ of BDP per month.

NFE: near fatal episodes. during the follow-up period were $1.11 \pm 1.70$ in Group A and $2.32 \pm 2.14$ in Group B (Table 2). Regular treatment with inhaled corticosteroids was started at various times (mean: 36.1 months) during the follow-up periods in ten patients from Group B who continue to survive. Another ten patients in Group B are still alive without treatment with BDP (Table 2).

Eight patients ( 6 male, 2 female) died in Group B during the follow-up period. There were no deaths in Group A. The mean period of observation between hospital discharge and death was $31.5 \pm 20.7$ months (range: $12-66 \mathrm{~m}$ ) (Table 2). Mean age among the cases who died was $52.1 \pm 19.8$ years old (range: $18-$ 80 y.o.).

The type of attack could be determined in 18 out of 19 Group A patients and 26 out of 28 Group B patients. Death occurred in five of 9 Group B patients who showed a rapidly progressive attack, defined as an attack which developed into a near fatal condition within two hours. Three of the 17 Group B patients who had a slowly progressive attack died. The death rate was higher among patients with rapid progression (Table 3). During follow-up periods, five of eight patients who died, died as result of their first near fatal episode after being

Table 2. Observation Period and Frequency of Admissions after Near Fatal Episodes

\begin{tabular}{|c|c|c|}
\hline & Group A & Group B \\
\hline $\begin{array}{l}\text { Mean dose of BDP } \\
\text { after NFE }(\mu \mathrm{g} / \text { day })\end{array}$ & $687(451)$ & \\
\hline $\begin{array}{l}\text { Observation period } \\
\text { after NFE (month) }\end{array}$ & $82.9(26.2)$ & $66.2(34.7)$ \\
\hline $\begin{array}{l}\text { Mean period } \\
\text { between NFE and death (month) }\end{array}$ & & $31.5(20.7)$ \\
\hline $\begin{array}{l}\text { Mean period } \\
\text { between NFE and initiation } \\
\text { of regular BDP treatment (month) }\end{array}$ & 0 & $36.1(23.1)$ \\
\hline $\begin{array}{l}\text { Frequency of admissions } \\
\text { after NFE }\end{array}$ & $1.11(1.02)$ & $2.32(2.14)$ \\
\hline
\end{tabular}

( ): SD

Group A was defined as patients who took various doses of BDP daily. Group B was defined as patients who were either not given BDP or who inhaled BDP infrequently, and patients who received less than one 120dose meter dose inhaler containing $6 \mathrm{mg}$ of BDP per month.

NFE: near fatal episodes.

Table 3. Differences in Prognosis between Group A and Group B Patients

\begin{tabular}{lcc}
\hline & \multicolumn{2}{c}{ Died/survived } \\
\cline { 2 - 3 } & Group A & Group B \\
\hline Rapidly progressive & $0 / 6$ & $5 / 9$ \\
Slowly progressive & $0 / 12$ & $3 / 17$ \\
Unknown & $0 / 1$ & $0 / 2$
\end{tabular}

Group A was defined as patients who took various doses of BDP daily. Group B was defined as patients who were either not given BDP or who inhaled BDP infrequently, and patients who received less than one 120-dose meter dose inhaler containing $6 \mathrm{mg}$ of BDP per month. 
discharged from hospital, one at the second episode and two at the third episodes.

\section{Discussion}

Asthma mortality and morbidity has not improved despite advances in our understanding of the pathogenesis of asthma and the introduction of new drugs $(1-3,11,12)$. Recent advances include the recognition of the role of increased bronchial hyperresponsiveness, which probably results from airway inflammation, and the introduction of inhaled corticosteroids in the treatment of asthma (4). Inhaled corticosteroids reduce bronchial hyperresponsiveness, and greatly improve asthma even in severe patients $(5,6)$. Recently proposed guidelines for the treatment of asthma also emphasize the early administration of inhaled corticosteroids together with on-going self-management plans (13-15).

Underestimation of the severity of the patient's asthma by their families, doctors and the patient himself, the overreliance on beta-agonist inhalers and the rapid progression of the asthma attack itself delay emergency treatment and thus result in subsequent death $(1-3,9,10)$. Furthermore, inadequate use of anti-inflammatory agents and beta-agonists may have affected the worldwide increase in death from asthma $(11,12,16)$. In particular, concern over the possible association between excessive use of the inhaled beta-agonist Fenoterol and death has been raised by several investigators (16-19). However, the true factors which are primarily responsible for asthma death is still a matter of controversy (20).

Previous studies on asthma mortality have identified a history of recent admissions to hospital with asthma and/or near fatal episodes and repeated admissions during the year prior to death as major risk factors for death from asthma $(1,2,8-10)$, and it has also been suggested that smoking and people over the age of 40 may be associated with higher mortality (21). It is therefore essential to identify and treat those patients who are at risk. Furthermore, it has been emphasized that specialized outpatient management, such as regular surveys by pulmonary physicians together with assessments of pulmonary function, are surprisingly important $(21,22)$.

In the present study, we investigated the long-term prognosis of patients who experienced near fatal episodes and who have been followed up regularly at Kobe City General Hospital. The results show that the long-term use of relatively low doses of inhaled corticosteroids may reduce the risk of death from asthma. Only those subjects who used no inhaled corticosteroids or who used them irregularly died during the follow-up periods.

However, it was not shown that the regular use of inhaled corticosteroids alone, without a self-management plan, can prevent death from asthma. We arbitrarily divided the patients into two groups, Group $\mathrm{A}$, consisting of patients who took various doses of BDP daily, and Group B, patients who were not treated with BDP daily or who were not prescribed the drug, the prognosis of the patients in the two groups was compared.

In Group A, the mean dose of BDP was $687 \mu \mathrm{g} /$ day with a minimum dose of $200 \mu \mathrm{g} / \mathrm{day}$, but this mean dose seemed to have a lower potential particularly in controlling severe cases of chronic asthma. This study group may not be well balanced for severity and compliance of patients. The survivors, however, may have been highly compliant with medical management. It is possible that factors other than continuous use of inhaled corticosteroids affected the results. Several potential limitations still remain because of the retrospective nature of this study.

The differences in the proportion of patients who had used systemic steroids over long periods of time might have been important, both within and between the two groups. However, the risk of death in patients who had been receiving oral steroids continuously seems to be higher than in patients who had not. It is unlikely that continuous use of small doses of oral steroids results in better prognosis because most long-term steroid users may well have refractory asthma and a low dose of oral steroid has a lower potential in improving the condition of the airway. On the other hand, it is particularly important to note that longterm steroid users who have been receiving BDP regularly, even at a low dose, survive.

Hummel and co-workers reported that high doses of inhaled steroids offer no further benefit over low doses in the maintenance treatment of severe steroid dependent asthma with a spacer device (23). These findings suggest that a good outcome is possible in severe asthma even with a fairly low dosage, if the drug is correctly administered. Even small doses of inhaled corticosteroids may well have potential in reducing the severity of airway inflammation. A recent Canadian study also suggested that inhaled corticosteroids are effective in preventing death and near fatal asthma (7), and further, their study seems to demonstrate a preventive effect of inhaled corticosteroids despite the low dose dispensed (7).

The present study also supports previous reports which have shown that the incidence of death is higher among patients with rapidly developing near fatal attack, in whom the bronchial hyperresponsiveness and diurnal variation of airway obstruction is suspected to be high $(2,3,24)$. However, Molfino et al pointed out that the risk of rapidly progressive fatal attack in some patients is not always related to the severity of the attack (25). It is not known what percentage of asthma deaths can be truly classified as the result of a rapid progressive attack and which mechanisms are responsible for these events. Airway narrowing in sudden onset and rapid progressive fatal asthma seem to be quite distinct from those in slow progressive fatal asthma $(26,27)$.

The present study shows, however, that the incidence of death is likely to be low even in patients who had experienced rapid progressive attack, if they have been given BDP every day. Regular use of inhaled corticosteroids seems to be essential in reducing the risk of death even among these patients. These findings may suggest that inflammation plays an important role in the pathogenesis of the increased airway hyperresponsiveness and the increased diurnal variation of airway obstruction even in patients with rapid progressive attack. In these patients, slight improvement of airway conditions may result in great improvement in their morbidity and mortality. 
Frequency of inhaled corticosteroid which prevent death from asthma in high risk patients, as well as the management of such patients remain unknown.

A multicenter, double blind, placebo controlled prospective study would clarify these questions, but would not be ethically acceptable. Hence there have been few studies designed to reduce hospital admission and death from asthma. Mayo and co-workers did, however, successfully design a program to reduce hospital admission for adult asthma (28). This included a vigorous medical regimen such as inhaled corticosteroids and an intensive education program emphasizing aggressive selfmanagement strategies for marked asthma exacerbation. Ruffin and co-workers also reported in their longitudinal study of near fatal asthma that there were no asthma deaths among patients who were given a treatment regimen which included short-term oral corticosteroids and inhaled corticosteroids with self-management plans. They adjusted the dose of BDP according to the level of bronchoconstriction (29). In recent proposed guidelines, conventional doses of inhaled corticosteroids are recommended for mild cases of adult asthma. In moderate and severe asthma, high doses of inhaled corticosteroids and the rescue use of short-term oral steroids are recommended to regain better control (13-15).

The present study suggests that the regular use of inhaled corticosteroids, even with low doses, may reduce the risk of death following near fatal asthmatic episodes. The further introduction of inhaled corticosteroids should have favorable effects on the epidemiology of asthma, bringing a measurable downward trend in asthma deaths.

\section{References}

1) British Thoracic Society: Death from asthma in two regions in England. BMJ 285: 1251, 1982.

2) Benatar SR. Fatal asthma. N Engl J Med 314: 423, 1986.

3) Strunk RC. Death due to asthma. New insight into sudden unexpected deaths, but focus remains on prevention. Am Rev Respir Dis 148: 550, 1993.

4) Barnes PJ. A new approach to the treatment of asthma. N Engl J Med 321: 1517, 1989.

5) Juniper EF, Kline PA, Vanzieleghem MA, Ramsdale EH, O Brien PM, Hargreve EH. Long-term effects of budesonide on airway responsiveness and clinical asthma severity in steroid-dependent asthma. Eur Respir J 3: 1122,1990

6) Horn CR, Clark TJH, Cochrane GM. Can the morbidity of asthma be reduced by high dose of inhaled therapy. Respir Med 84: 61, 1990.

7) Ernst P, Spitzer WO, Suissa S, et al. Risk of fatal and near-fatal asthma in relation to inhaled corticosteroid use. JAMA 268: 3462, 1992.

8) Westerman DE, Benatar SR, Potgieter PD, Ferguson AD. Identification of the high risk asthmatic patients; Experience with 39 patients undergoing ventilation for status asthmatics. Am J Med 66: 565, 1978.

9) Rea HH, Scragg R, Jackson R, Beaglehole R, Fenwick J, Sutherland DC. A case controlled study of death from asthma. Thorax 41: 833, 1986.

10) Strunk RC. Identification of the fatality prone subjects with asthma. J Allergy Clin Immunol 83: 477, 1989.

11) Whitelaw LA. Asthma death. Chest 99: 1507, 1991.

12) MitchelEA. Is current treatment increasing asthma mortality and morbidity? Thorax 44: 81, 1989.

13) Hargreeve EH, Dolovich J, Newhouse MT. The assessment and treatment of asthma; a conference report. J Allergy Clin Immunol 85: 1098, 1990.

14) National Asthma Education Program. Expert Panel Report: Guideline for the Diagnosis and Management of Asthma. Publication 91-3024, US Dept. of Health and Human Services, Bethesda, MD, 1991.

15) Guidelines on the management of asthma. Thorax $\mathbf{4 8}$ (Suppl), 1993.

16) Sly RM. Mortality from asthma 1979-1984. J Allergy Clin Immunol 82: $705,1988$.

17) Sears MR, Taylor DR, Print CG, et al. Regular inhaled beta-agonist treatment in bronchial asthma. Lancet 336: 1391, 1990.

18) Grainger J, Woodmann K, Pearce N, et al. Prescribed fenoterol and death from asthma in New Zealand, 1981-7: a further case control study. Thorax 46: $105,1991$.

19) Ernst P, Habbick B, Suissa $S$, et al. Is the association between inhaled beta-agaonist use and life threatening asthma because of confounding by severity? Am Rev Respir Dis 148: 75, 1993.

20) Mulen M, Mullen B, Carey M: The association between beta-agonist use and death from asthma: A meta-analytic integration of case-control studies. JAMA 270: 1842, 1993.

21) Marquette $\mathrm{CH}$, Saulnier F, Leroy $\mathrm{O}$, et al. Long-term prognosis of near fatal asthma. A 6-year follow-up study of 145 asthmatic patients who underwent mechanical ventilation for a near fatal attack of asthma. Am Rev Respir Dis 146: 76, 1992.

22) Molfino NA, Nannini LJ, Rebuck AS, Slutsky AS. The fatality prone asthma patients; follow up study after near fatal attacks. Chest 101: 621, 1992.

23) Hummel $S$, Leftonen L. Comparison of oral-steroids sparing by high dose and low dose inhaled steroid in maintenance treatment of severe asthma. Lancet 340: 1483, 1992.

24) Pouw EN. Clinical assessment after a life threatening attack of asthma; the role of bronchial hyperreactivity. Eur Respir J 99: 861, 1990.

25) Molfino NA, Nannini LJ, Martelli AN, Slutsky AS. Respiratory arrest in near fatal asthma. N Engl J Med 324: 285, 1991.

26) Wasserfalen J, Schaller M, Feihl F, Perret CH. Sudden asphyxic asthma; a distinct entity. Am Rev Respir Dis 142: 108, 1990.

27) Sur S, Crotty TB, Kephart GM, et al. Sudden-onset fatal asthma. A distinct entity with few eosinophils and relatively more neutrophils in the airway submucosa? Am Rev Respir Dis 148: 713, 1993.

28) Mayo PH, Richman J, Harris HW. Results of a program to reduce admission for adult asthma. Ann Int Med 112: 864, 1990.

29) Ruffin RE, Latimer KM, Schembri DA. Longitudinal study of near fatal asthma. Chest 99: 77, 1991. 